\title{
AS POSSÍVEIS MODIFICAÇÕES NO CRIME DE ESTUPRO NO PRISMA DA PROPOSTA DE EMENDA CONSTITUCIONAL № 64/2016
}

\author{
Beatriz Rezende Pereira Souza, Fábio Ferreira Morong \\ Universidade do Oeste Paulista - UNOESTE, curso de Direito, Presidente Prudente, SP. E-mail: \\ beatriz_rezende97@hotmail.com; fabiomorong@hotmail.com
}

\begin{abstract}
RESUMO
O presente artigo objetiva explanar a Proposta de Emenda Constitucional 64/2016, dado que o atual ordenamento encontra-se negligente junto ás vítimas relativas ao crime de estupro, desencadeando um descompasso entre a lei e a sociedade. Ademais, o estudo visa uma melhor compreensão e reflexão, buscando uma assimilação concisa de seu teor, composto pela possibilidade do crime de estupro tornar-se imprescritível e inafiançável ao alterar a atual redação do inciso XLII do artigo 5o da Carta Magna. O método aplicado foi o dedutivo legal, baseado na interpretação da Constituição, legislação, teorias, jurisprudências e doutrinas, com abordagem hermenêutica-dialética. Conclui-se que a proposta de emenda à constituição de fato propiciará maior segurança às vítimas do delito, de modo que as alterações apresentadas são coerentes com a evolução social e certamente proporciona uma resposta às fragilidades legislativa e social.

Palavras-chave: Lei. Estupro. Impunidade. Prescrição. Vítima. PEC 64/2016.

\section{THE POSSIBLE MODIFICATIONS IN THE CRIME OF RAPE IN THE PRISM OF THE PROPOSAL FOR CONSTITUTIONAL AMENDMENT №64/2016}

\begin{abstract}
The present article aims to explain Constitutional Amendment Proposal 64/2016, given that the current system is negligent along with the victims related to the crime of rape, triggering a mismatch between law and society. In addition, the study seeks a better understanding and reflection, seeking a concise assimilation of its content, composed of the possibility of the crime of rape becoming imprescriptible and non-enforceable by changing the current wording of paragraph XLII of article 5 of the Constitution. The method applied was the legal deductive, based on the interpretation of the Constitution, legislation, theories, jurisprudence and doctrines, with a hermeneutic-dialectic approach. It is concluded that the proposed amendment to the de facto constitution will provide greater security to the victims of crime, so that the amendments presented are consistent with social developments and certainly provide a response to legislative and social weaknesses.
\end{abstract}

Keywords: Law. Rape. Impunity. Imprint. Victim. PEC 64/2016.

\section{INTRODUÇÃO}

É certo que a prática do estupro existe desde os tempos mais remotos. No Brasil, o início e fortificação desse ato, que sempre fora tratado com mais naturalidade do que com indignação, deu-se após sua colonização, onde mulheres indígenas eram estupradas comumente, sendo uma 
verdadeira "terra de ninguém". Além disso, houve uma maior visualização do sexo feminino como propriedade a partir da chegada dos negros ao Brasil, que eram vendidos como objetos ou peças para posse de seus Senhores. A partir daí, houve uma diferenciação entre mulheres honestas e ideais para gerar sua prole, e mulheres uteis para a satisfação da lascívia.

Em virtude da mudança na percepção quanto ao crime de estupro na atual sociedade, no dia 09 de maio deste ano, a Comissão de Constituição, Justiça e Cidadania do Senado Federal emitiu parecer favorável a proposta de emenda constitucional (PEC) no 64/2016, liderada pelo senador Jorge Viana entre outros. A proposta de emenda à Constituição inclui ao inciso XLII do artigo 5ㅇ da Carta Magna o crime de estupro, a fim de que este se transforme em imprescritível e inafiançável, assim como no crime de racismo.

O presente artigo objetiva explanar a Proposta de Emenda Constitucional 64/2016, dado que $o$ atual ordenamento encontra-se negligente junto ás vítimas relativas ao crime de estupro, desencadeando um descompasso entre a lei e a sociedade. Ademais, o estudo visa uma melhor compreensão e reflexão, buscando uma assimilação concisa de seu teor, composto pela possibilidade do crime de estupro tornar-se imprescritível e inafiançável ao alterar a atual redação do inciso XLII do artigo 5o da Carta Magna.

\section{METODOLOGIA}

O presente trabalho foi baseado na interpretação da Constituição, legislação, teorias, jurisprudências e doutrinas, com abordagem hermenêutica-dialética. $O$ método aplicado neste trabalho é o dedutivo, que de um modo geral, a partir de princípios, normas constitucionais, leis ou teorias consideradas verdadeiras e indiscutíveis, prediz a ocorrência de casos particulares com base na lógica, partindo de princípios reconhecidos como verdadeiros e indiscutíveis e possibilita chegar a conclusões de maneira puramente formal, ou seja, em virtude unicamente de sua lógica (GIL, 2008, p. 9). A abordagem é a hermenêutica-dialética. A hermenêutica pode ser considerada como um técnica que compreende textos, em um sentido amplo: biografia, livro, artigo, narrativa, documento, dentre outros. Por sua vez, a abordagem dialética procura nos fatos os núcleos obscuros e contraditórios para realizar uma crítica em relação aos mesmos. O pensamento dialético compreende que a análise dos significados deve ser feita considerando as práticas sociais e ressaltando o condicionamento histórico das falas (Minayo, 2010).

\section{DA LEI 12.015/2009 E SUAS PRINCIPAIS MODIFICAÇÕES}

Antes de abarcar o tema principal, faz-se necessário uma sucinta explicação do desenvolvimento jurídico do crime de estupro. O advento da Lei 12.015/2009 trouxe significativas mudanças, a começar pela revogação do artigo 214 do Código Penal, unificando-o com o artigo 213 do mesmo diploma, fazendo com que o estupro torne-se crime comum. Ou seja, não mais exigindo a elementar do tipo "homem" como sujeito ativo e "mulher" como sujeito passivo, sendo a liberdade sexual o bem jurídico tutelado, fazendo com que o sexo do ofendido seja desinteressante para a caracterização do delito (BITENCOURT, 2015

No que tange à prova da consumação, não há mais necessidade da cópula vagínica, pois o legislador ao optar por uma redação genérica tornou o ato da relação sexual mais abrangente, já havendo a possibilidade de ser considerado como consumação do estupro alguns atos libidinosos diversos da conjunção carnal, podendo admitir também a forma tentada (NUCCI, 2014). 
O aspecto vulnerável também recebeu modificações. $O$ antigo diploma dispunha que o estupro cometido contra menor de 14 anos era "Estupro-Presumido", sendo o fator "vontade" relevante. Agora o art.217-A tem como caput: "Ter conjunção carnal ou praticar outro ato libidinoso com menor de 14 (catorze) anos".

Com isso, a nova redação não adere á vontade volitiva da vítima, mas sim a tenra idade (14

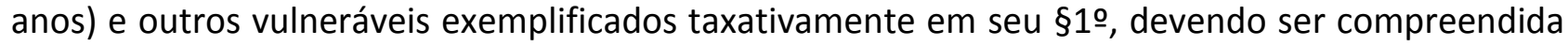
restritivamente de acordo com a fragilidade física ou mental da vítima, no caso concreto.

\section{DA LEI 12.650/2012 DE 17 DE MAIO DE 2012 - LEI JOANNA MARANHÃO}

A lei sancionada alterou o prazo prescricional de crimes sexuais contra crianças e adolescentes, buscando cuidar de forma especial destes casos. O prazo que antes iniciava-se a partir da prática do crime, agora com o novo inciso $\mathrm{V}$ acrescido ao artigo 111 do Código penal, dispõe o seguinte:

Art. 111 - A prescrição, antes de transitar em julgado a sentença final, começa a correr: $\mathrm{V}$ - nos crimes contra a dignidade sexual de crianças e adolescentes, previstos neste Código ou em legislação especial, da data em que a vítima completar 18 (dezoito) anos, salvo se a esse tempo já houver sido proposta a ação penal.

A alteração ocorreu em homenagem a nadadora Joanna Maranhão que denunciou o abuso sofrido na infância pelo seu treinador. O legislador, ao usar o caso como retrato para a alteração teve como objetivo diminuir a impunidade dos crimes dessa espécie, preconizando uma punição mais severa ao criminoso.

A ministra da Secretaria de Direitos Humanos da Presidência da República, Maria do Rosário Nunes (2012) ainda acrescenta que, "Essa conquista nos fortalece para continuar lutando. É preciso proteger a menina que hoje é mulher e só agora teve a coragem de denunciar".

A mudança implantada visa também a erradicação da exploração sexual no nosso país, afastando-as completamente da miséria e da vulnerabilidade social. Nota-se que tal norma apresenta um importante progresso no sentido de propiciar maior atenção e preocupação frente às impunidades e falhas legislativas relacionadas aos delitos desta natureza.

\section{DA NECESSIDADE DA APROVAÇÃO DO PROJETO DE EMENDA CONSTITUCIONAL no 64/2016}

Inicialmente, a fim de que se tenha um entendimento conciso do assunto abarcado, faz-se necessária uma melhor explicação do que é uma emenda constitucional.

Segundo Mascarenhas (apud CASTRO, 2017, p. 03), a emenda constitucional está acima de todas as normas, sendo:

A emenda constitucional, assim, situa-se em um plano acima das demais espécies normativas, uma vez que, após a sua aprovação através de processo legislativo específico, ela adquire a mesma natureza jurídica e o mesmo posicionamento hierárquico das normas constitucionais originárias.

A possível adesão da emenda constitucional trará a possibilidade do crime de estupro tornar-se imprescritível e inafiançável. Atualmente, a prescrição aos olhos de Masson (2014, p. 932), caracteriza-se como "a perda da pretensão punitiva ou da pretensão executória em face da 
inércia do Estado durante determinado tempo legalmente previsto". A fiança por sua vez, é uma forma de caução, uma garantia real dada em dinheiro a fim de que o acusado ou réu permaneça em liberdade provisoriamente, ou seja, até sua sentença.

Com a alteração, o inciso XLII do artigo 5 da Constituição Federal estabelecerá que: "XLII a prática do racismo e do estupro constitui crime inafiançável e imprescritível, sujeito á pena de reclusão, nos termos da lei".

Ao converter-se em crime imprescritível, a pretensão executória estatal é ilimitada, ficando o criminoso plenamente suscetível a penalização do Estado. Essa possibilidade faz com que a vítima possa denunciar o crime e um momento em que ela se sinta mais preparada. Não é possível avaliar um tempo específico para que a vítima se recupere da violência, sendo variável de acordo com cada caso. $O$ estupro é uma cicatriz profunda, que pode ser amenizada, porém, nunca será apagada.

Além da maturidade emocional, esta se depara com uma marginalização investida pela sociedade a ela. É comum a vítima receber questionamentos referentes a sua conduta no momento do ilícito, e isso gera uma barreira entre o Estado e a vítima impossibilitando-a de requerer o que é seu por direito. Vale a pena refletir sobre as considerações do desembargador Lécio Resende (1992):

É irrelevante à existência do estupro o estado ou qualidade da vítima: solteira, casada, virgem ou não, honesta, devassa ou prostituta, porque, em qualquer caso, tem a mulher direito à tutela da lei, visto que a proteção se dirige ao direito de livre disposição do próprio corpo. [...] Não importa seja a vítima solteira, casada ou viúva, uma vestal inatacável ou uma meretriz de baixa formação moral. Em qualquer hipótese é ela senhora de seu corpo e só se entregará livremente, como, quando, onde e a quem for de seu agrado.

É válido reforçar que a vítima nunca deve ser questionada, muito menos responsabilizada pelo crime, eis que isso faz com que a maioria dos casos de estupro não sejam reportados. Em 2014, o Instituto de Pesquisa Aplicada (IPEA, 2014), publicou um estudo relatando que $70 \%$ dos casos são cometidos contra crianças e adolescentes, sendo que $24,1 \%$ dos criminosos são os próprios pais e padrastos, e $32,2 \%$ são amigos e conhecidos da vitima. Somente na idade adulta, o percentual é de $60,5 \%$.

Nota-se que o Estado torna-se o segundo violentador da vítima ao tomar essa postura, dando pouca credibilidade a palavra da vítima, sujeitando-a a inúmeros procedimentos e situações constrangedoras até que se alcance um resultado contundente. Nesse sentido é a afirmativa do Senador Jorge Viana (2017) na Proposta de Emenda à Constituição aduzindo que "quando uma mulher vai denunciar que sofreu um estupro ela vira vítima de novo, porque perguntam que roupa ela estava usando, se ela tinha bebido, então até isso nós vamos ter que mudar".

Pois bem, é certo que além do constrangimento social que a vitima sofre, esta sente o temor de uma possível vingança vinda de seu agressor, porém, a referida Lei 8.072/1990 em seu artigo 10 nos incisos V e VI, prevê que o crime de estupro e estupro praticado contra vulneráveis caracteriza-se como crime hediondo, que por corolário the é vetada a possibilidade de fiança, assim como fora descrito no artigo 2 으, inciso II do mesmo dispositivo. 
Assim, ao propiciar o cárcere sem disposição de fiança ao criminoso, acaba por ocasionar uma maior segurança á vítima no âmbito geral e principalmente em casos específicos, como em situações onde o agressor encontra-se no próprio ambiente familiar ou tem contato direto com ela, oferecendo a esta um maior risco de sofrer novos abusos. Se esta situação já pode ser considerada como crítica, em casos que envolvem crianças e adolescentes a situação é ainda mais temerosa, exigindo maior atenção (VIANA, 2016).

Ao dispor o crime como inafiançável o legislador está buscando dar maior efetividade na proteção e integridade física e emocional da vítima, pois, o criminoso não terá a possibilidade de acompanhar o processo em liberdade, estando preso até que seja prolatada sua sentença final. Assim, ainda que existam divergências a respeito, é certo que não somente a vítima terá uma maior segurança imediata em relação a eventual vingança do agressor, como também haverá um certo zelo pela segurança de futuras e eventuais vítimas.

De outro lado, a objetiva alteração no dispositivo não é uma garantia integral de que assim a vítima obterá a segurança jurídica necessária. $O$ assunto posto em tela vai além do âmbito jurisdicional e está diretamente ligado à educação social, sendo esta basilar para que o crime de estupro seja evitado ao invés de remediado ou agravado em termos legais. É imperativa a ideia que de que a cultura do estupro deve ser extinta, conjuntamente com a desigualdade entre os gêneros, falta de respeito e a falta de amor ao próximo.

\section{CONCLUSÃO}

O presente artigo objetiva realizar uma melhor compreensão e análise do texto oferecido pela proposta de emenda à constituição $\mathrm{n}$ 0 64/2016, tal como refletir sobre o tema posto em tela.

A proposta de emenda constitucional apresentada ao Senado Federal, em caso de aprovação proporcionará a aquele que cometer o crime de estupro uma maior severidade em sua punição, pois este será classificado como autor de um crime imprescritível e inafiançável. Essa medida trará uma maior seguridade ás vitimas, além do mais, tem o intuito de encorajar a denuncia do crime, mesmo que esta se realize tempos após o fato. Essa atitude afeta diretamente o criminoso, que não terá brechas de se desvencilhar das vistas da lei.

No mais, a proposta de emenda à constituição buscou atender as deficiências que a lei apresenta quanto sua eficácia e eficiência, levando em conta o atual ordenamento que exige celeridade para que o criminoso possa ser penalizado. O lapso temporal definido acarreta a impunidade com mais frequência, transparecendo o entendimento de que a justiça tardia não é justiça.

Logo, é perceptível a fundamentalidade que a proposta de emenda constitucional $\mathrm{n}$ ㅇ 64/2016 apresenta, fazendo-se essencial sua aprovação e aplicação para que assim a legislação atenda fielmente as fragilidades sociais consistentes na atualidade, mas que estão presentes há muito tempo.

\section{REFERÊNCIAS}

BITENCOURT, Cesar Roberto. Código Penal Comentado . 9ạed. São Paulo, Editora Saraiva, 2015. Disponível em: <https://integrada.minhabiblioteca.com.br/\#/books/9788502626522/cfi/0 > Acesso em: 01 de Ago. 2017. 
BRASIL. Constituição. (1988). Constituição da República Federativa do Brasil. Brasília. Senado Federal, 2016.

BRASIL. Tribunal de Justiça do Distrito Federal (2o Turma Criminal). Apelação Criminal. APR 0 DF. Relator: Ministro Lécio Resende. Julgamento: 15/10/1992. Data de Publicação: 11/11/1992, DJU Pág. $\quad 36.730 \quad$ Seção: $2 . \quad$ Disponível em: < https://tjdf.jusbrasil.com.br/jurisprudencia/5635392/apelacao-criminal-apr-0-df-tjdf\#! >. Acesso em: 03 julh. 2017.

BRASIL. Senado Federal. Proposta de Emenda à Constituição no 64, de 2016. Autor: Senador Jorge Viana et al. Disponível em: < https://www25.senado.leg.br/web/atividade/materias//materia/127681 > Acesso em: 03 julh. 2017.

DE CASTRO, Rafael Alves. Proposta de Emenda à Constituição № 65/2012 ViabilidadeConsequências Fáticas. p. 03, 2017. Trabalho de Conclusão de Curso (Bacharelado em Direito) Universidade do Oeste Paulista - UNOESTE- Presidente Prudente/SP, 2016. [Orientador: Prof. Dr. Fábio Ferreira Morong].

DE SOUZA, Silberth Steffany. Lei de Estupro e suas Consequências. Disponível em < http://www.ambito-

juridico.com.br/site/index.php?n_link=revista_artigos_leitura\&artigo_id=8236 >. Acesso em: 03 julh. 2017.

GIL, Antônio Carlos. Métodos e Técnicas de Pesquisa Social. 6a Ed. São Paulo: Atlas, 2008. Acesso em: 04 set. 2017.

GOMBATA, Marsileia. Violência: Estupro, o crime que até a lei oculta. Disponível em: < https://www.cartacapital.com.br/revista/905/estupro-o-crime-que-ate-a-lei-oculta>. Acesso em: 03 julh. 2017.

INSTITUTO DE ECÔNOMIA APLICADA. Crianças e adolescentes são 70\% das vítimas de estupro. Disponível em: < http://www.ipea.gov.br/portal/index.php?option=com_content\&view=article\&id=21848\&catid=8 \&ltemid=6 >. Acesso em: 17 julh. 2017.

JUNGMANN, Mariana. Senado aprova em primeiro turno PEC que torna estupro crime sem prescrição. Disponível em: <http://agenciabrasil.ebc.com.br/politica/noticia/2017-05/senadoaprova-em-primeiro-turno-pec-que-torna-estupro-crime-sem-prescricao > Acesso em: 03 ago. 2017.

LEI № 8.072, DE 25 DE JULHO DE 1990. Lei dos Crimes Hediondos. Disponível em: <http://www.planalto.gov.br/ccivil_03/leis/L8072.htm >. Acesso em: 31 agos. 2017.

MARQUES, Archimedes José Melo. Crimes de Estupro :Leis e Direito. Infoescola. Disponível em: < http://www.infoescola.com/direito/crime-de-estupro/ >. Acesso em: 03 julh. 2017. 
MASSON, Cleber. Prescrição. In: MASSON, Cleber. Autor:MASSON, Cleber. Direito Penal Esquematizado, parte geral. 8a ed. São Paulo, Editora Método,2014. Vol. 1. Cap. 46. p. 932.

MINAYO, Maria Cecília de Souza (org.). Pesquisa social: teoria, método e criatividade. 29. ed. Petrópolis, RJ: Vozes, 2010. (Coleção temas sociais). Resenha. Acesso em: 04 set. 2017.

NUCCI, Guilherme. O crime de estupro sob o prisma da Lei 12.015/2009. Disponível em: < http://www.guilhermenucci.com.br/artigo/o-crime-de-estupro-sob-o-prisma-da-lei-12-0152009 >. Acesso em: 03 julh. 2017.

PARANÁ. Ministério Público. CAOPCAE - Área da Criança e do Adolescente. Lei no 12.650/2012, de 17 de maio de 2012 - Lei Joanna Maranhão. 2012. Disponível em: < http://www.crianca.mppr.mp.br/modules/noticias/article.php?storyid=204 >. Acesso em: 08 ago. 2017. 